\title{
North American survey and systematic review on caudal Septoplasty
}

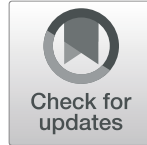

\author{
Béatrice Voizard@, Mélanie Theriault, Selma Lazizi and Sami P. Moubayed
}

\begin{abstract}
Background: Surgical correction of caudal septal deviation is a technically challenging step of functional rhinoplasty. Multiple surgical techniques have been described in the literature but comparing the efficacy of each in relieving obstruction presents a challenge. Outcome measures are necessary to adequately compare techniques. This study aims to describe the current caudal septoplasty techniques of Otolaryngologists and Facial plastic and reconstructive surgeons (FPRS), as well as their use of outcome measures, and to compare these practices with surgical trends described in the literature.

Methods: An online survey was sent to three Otolaryngology and FPRS associations in Canada and the United States. A systematic review was conducted on SCOPUS and PubMed to classify the caudal septoplasty techniques described in the literature and the outcome measurement tools used.
\end{abstract}

Results: Our survey identified that caudal septoplasty is more commonly performed by surgeons with an FPRS training background. The most common techniques were the swinging door technique (69.5\%), extracorporeal septoplasy (46.7\%), cartilage scoring (45.3\%), and splinting with bone (25.4\%). Despite using a vast array of surgical techniques, North American physicians rarely rely on standardized outcome assessment tools. Patient reported outcome measures (PROMs) are used almost twice as frequently in the literature as they are by surgeons in their clinical practice.

Conclusion: We recommend that future studies of caudal septoplasty include an assessment of both form and function using a validated PROM such as the Standardized Cosmesis and Health Nasal Outcomes Survey.

Keywords: Nasal obstruction, Patient reported outcome measures, Caudal septal deviation, Anterior septal deviation, Septoplasty, Septorhinoplasty

\section{Background}

Caudal septal deviation is defined as deviation of the anterior most portion of the nasal septum. (Fig. 1) In addition to functional symptoms, caudal septal deviation can cause significant cosmetic deformities, including

\footnotetext{
* Correspondence: sp.moubayed@umontreal.ca

This paper has been presented at the following meetings1. Université de Montréal Otolaryngology - Head and Neck Surgery Program Research Day. Montréal, QC. (April 2018)2. Canadian Society of Otolaryngology-Head and Neck Surgery 73rd Annual Meeting. Edmonton, AB (June 2019)3. Quebec Otolaryngology - Head and Neck Surgery Association's Annual Meeting. Montreal, QC. (October 2019)

Department of Surgery, Division of Otolaryngology - Head and Neck Surgery, Université de Montréal, 5400 Gouin Ouest Montreal, Quebec, Canada
}

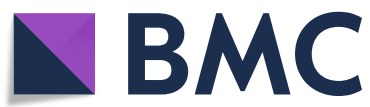

(c) The Author(s). 2020 Open Access This article is licensed under a Creative Commons Attribution 4.0 International License, which permits use, sharing, adaptation, distribution and reproduction in any medium or format, as long as you give appropriate credit to the original author(s) and the source, provide a link to the Creative Commons licence, and indicate if changes were made. The images or other third party material in this article are included in the article's Creative Commons licence, unless indicated otherwise in a credit line to the material. If material is not included in the article's Creative Commons licence and your intended use is not permitted by statutory regulation or exceeds the permitted use, you will need to obtain permission directly from the copyright holder. To view a copy of this licence, visit http://creativecommons.org/licenses/by/4.0/ The Creative Commons Public Domain Dedication waiver (http://creativecommons.org/publicdomain/zero/1.0/) applies to the data made available in this article, unless otherwise stated in a credit line to the data. lobule deviation, tip ptosis, and deformity of the middle one-third of the nose $[1,2]$. Caudal septal deviation differs from traditional septal deviation in that it involves a portion of the septum that contributes to the nasal valve area and the support of the nasal tip [1].

Consequently, surgical correction of caudal septal deviation is technically challenging and classifies as a functional rhinoplasty procedure because of its impact on the external nasal valve. Removal of the deviated caudal nasal septum results in loss of tip support, shortening of the columella and complications ranging from tip ptosis [1] to severe valve collapse. Inadequate surgical correction can cause persistence of nasal obstruction postoperatively [3]. 


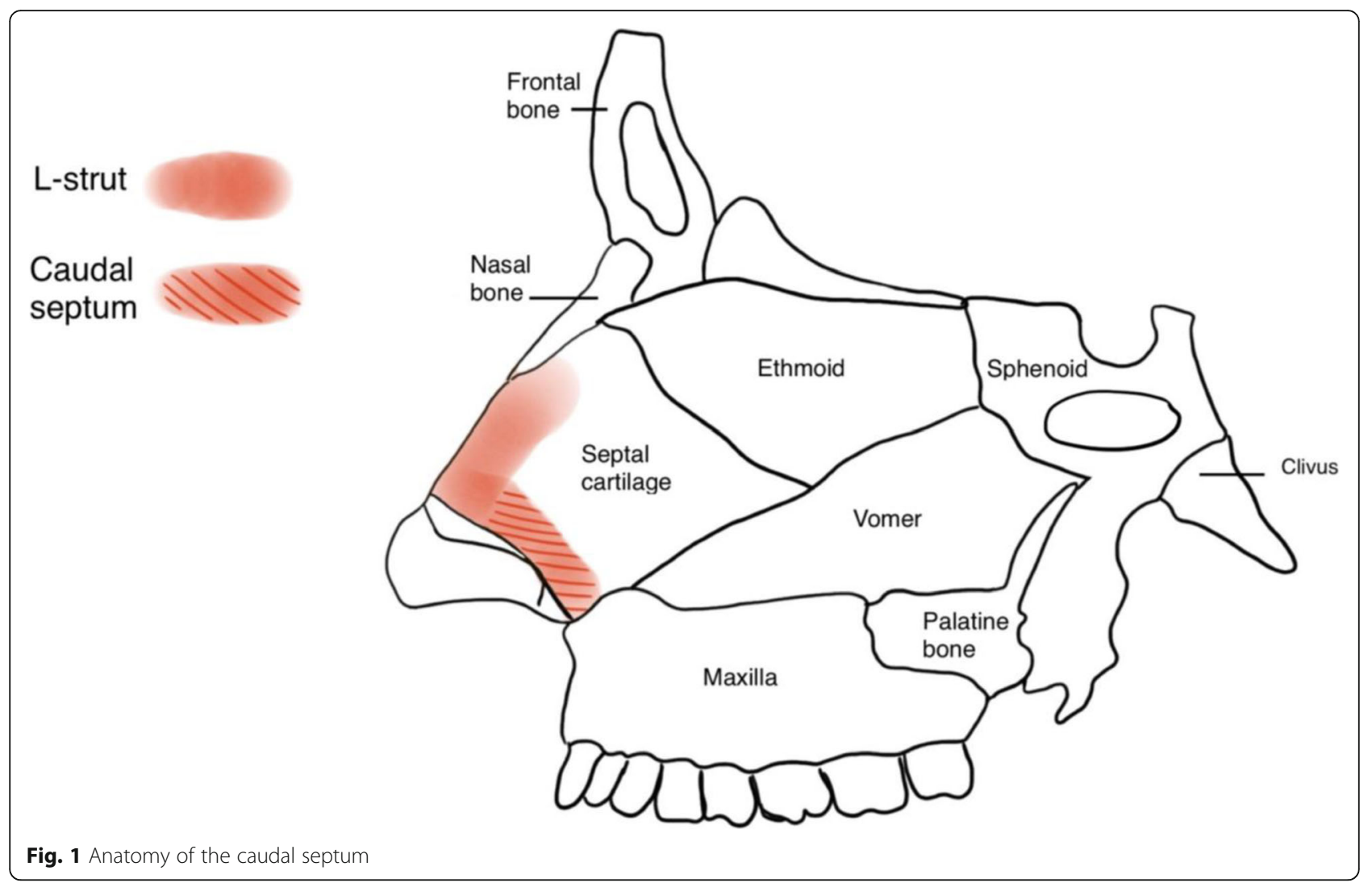

Multiple different surgical techniques have been described in the literature but comparing the efficacy of each in relieving functional symptoms presents a challenge. Objective parameters measured by acoustic rhinometry (AR) and rhinomanometry (RM) do not correlate with patients' perceived sensation of obstruction [4]. Visual analog scales (VAS) and patientreported outcome measures (PROMs) were conceived to collect standardized assessments of each patient's subjective symptoms and overall satisfaction in the preoperative and postoperative periods [5]. The Standardized Cosmesis and Health Nasal Outcomes Survey (SCHNOS) is a PROM that meets international methodological guidelines that has been validated specifically for the evaluation of cosmetic and functional outcomes after septorhinoplasty. The use of PROMs, VAS, AR and RM to report functional outcomes after caudal septoplasty varies widely in the literature.

The primary objective of this study was to describe the current caudal septoplasty techniques of otolaryngologists and facial plastic surgeons, as well as their use of outcome measures.

The secondary objective was to compare these practices with the surgical techniques and outcome measures described in the literature, by conducting a systematic review.

\section{Methods}

Scientific and ethics committee approval to undergo this project was obtained at our institution (Hopital Maisonneuve Rosemont), followed by approval from each surveyed medical association. An English or French, 9question survey requiring on average $1,5 \mathrm{~min}$ to complete was sent via email. The survey was designed using web survey development cloud base SurveyMonkey (www.surveymonkey.com, SurveyMonkey, Palo Alto, $\mathrm{CA}$ ). The survey was distributed via email to members of the following associations; the Association of Otolaryngology-Head and Neck Surgery of Quebec (ORLQC), the Canadian Society of OtolaryngologyHead and Neck Surgery (CSOHNS) and the American Association of Facial Plastic and Reconstructive Surgery (AAFPRS).

Each association received a cover letter describing the purpose of the survey and containing a link to the survey. Participants did not receive any compensation. The survey links were kept active for 3 months after the last email was sent out to the members by their association. The respondents were prevented from responding more than once by the online platform SurveyMonkey.

The survey included questions regarding demographic characteristics such as current practice location, country in which residency was completed, completion of a 
fellowship in facial plastic and reconstructive surgery, exposition to extracorporeal septoplasty during training, type of practice (academic, community, other), years of practice and number of patients with caudal septal deviation seen per month. Respondents were then asked to state how they evaluate nasal obstruction (history, physical examination, standardized questionnaire, airflow measurements, other) and the technique they use to treat caudal septal deviation (scoring, swinging door, splinting with bone, extracorporeal septoplasty, other). Respondents were allowed to select multiple answers to this question, since many techniques include combinations.

We then conducted a systematic literature review following the PRISMA statement guidelines $[6,7]$. The two databases used were PubMed and SCOPUS. The keywords used were ["caudal deviation" OR "caudal septal deviation" OR "anterior deviation" OR "anterior septal deviation"]. No limitations were added. All studies published in French or English between 1954 and 2018 were included.
All included studies met the following criteria: articles including a description of a surgical technique (either septoplasty or septorhinoplasty) aiming to correct caudal septal deviation; procedures addressing primarily functional symptoms; articles providing enough detail to understand the steps of the procedure and to differentiate it from other techniques; articles detailing how functional outcomes were evaluated; articles stating the number of patients on which the outcomes were measured, and stating the number of controls, if controls were used.

The exclusion criteria were the following: articles not in French or English, procedures addressing non-caudal nasal septal deviations; articles evaluating only or primarily cosmetic outcomes. Literature reviews, correspondences, descriptions of techniques without any outcome evaluation, and book chapters or sections were excluded from this review.

After identifying records through database researching and removing duplicates, abstracts were screened for eligibility by two independent readers and classified as

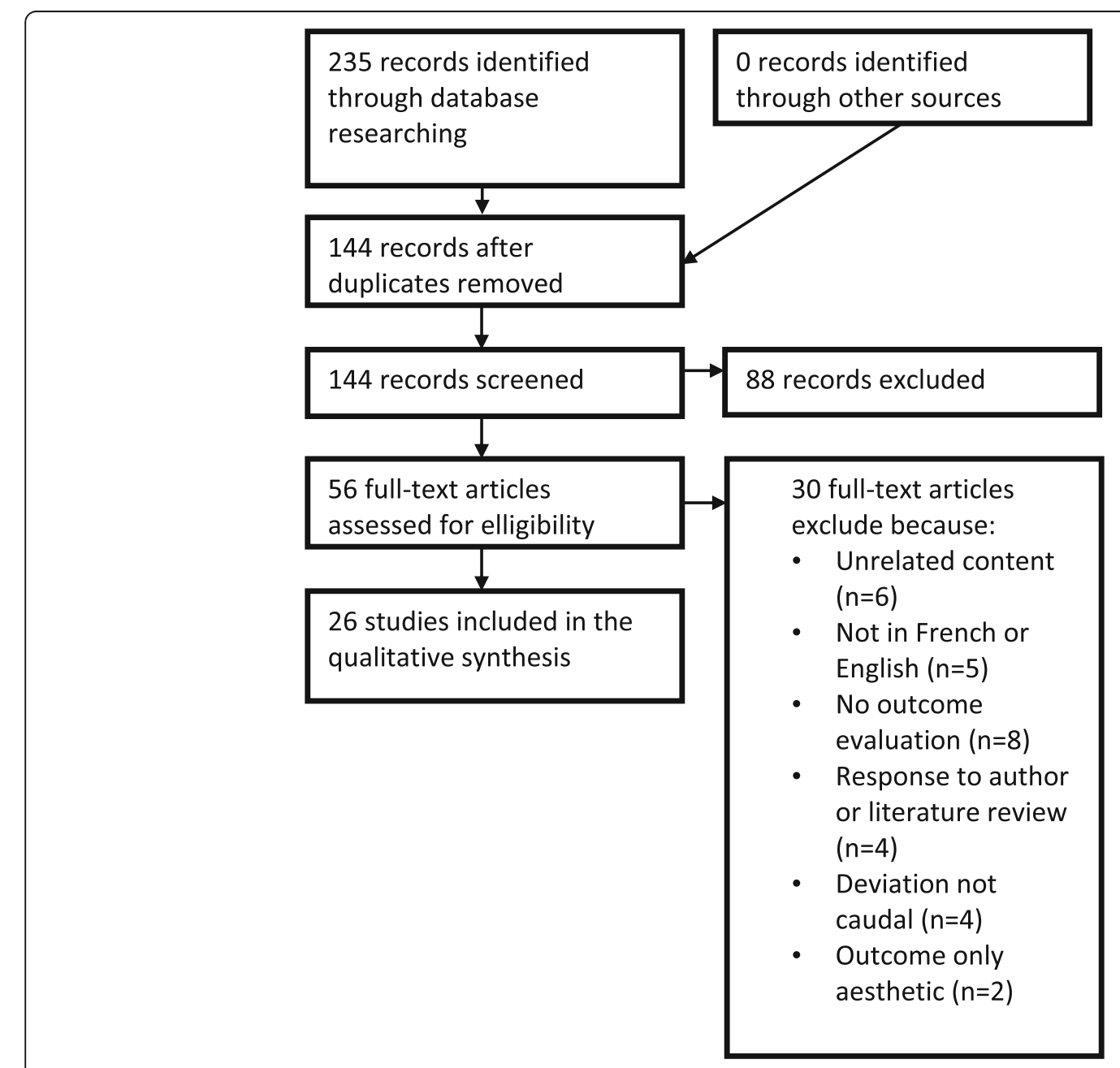

Fig. 2 Literature Review Flow Diagram 
"included", "excluded" or "neither excluded or included". A tertiary, independent reader further classified the "neither excluded or included" abstracts, deciding whether they would be included or not. Included full-text articles were read and analyzed, and further articles were excluded. A qualitative synthesis is presented in this article. Figure 2 is a flow diagram representing the number of records identified, included and excluded, and reason for exclusion when applicable.

\section{Results}

\section{Survey}

Table 1 regroups the demographic characteristics of all respondents. Out of 413 respondents, 87 were from ORLQC, 108 were from CSOHNS and 218 were from AAFPRS. This represents an estimated response rate of $36.9,19.5$ and $9 \%$, respectively. The vast majority of respondents performed caudal septoplasty $(n=3277$;

Table 1 Demographic characteristics of respondents

\begin{tabular}{|c|c|c|}
\hline & Number of respondents & Percentage of respondents \\
\hline \multicolumn{3}{|l|}{ Society of origin } \\
\hline ORL QC & 87 & $21.1 \%$ \\
\hline CSOHNS & 108 & $26.2 \%$ \\
\hline AAFPRS & 218 & $52.8 \%$ \\
\hline \multicolumn{3}{|l|}{ Training } \\
\hline Canada & 193 & $46.7 \%$ \\
\hline US & 210 & $50.8 \%$ \\
\hline Other & 10 & $2.5 \%$ \\
\hline \multicolumn{3}{|c|}{ Performing caudal septoplasty } \\
\hline Yes & 377 & $91.3 \%$ \\
\hline No & 36 & $8.7 \%$ \\
\hline \multicolumn{3}{|c|}{ FPRS fellowship completion } \\
\hline Yes & 212 & $51.3 \%$ \\
\hline No & 201 & $48.7 \%$ \\
\hline \multicolumn{3}{|l|}{ Practice setting } \\
\hline Academic & 132 & $32 \%$ \\
\hline Community & 224 & $54.2 \%$ \\
\hline Other & 57 & $13.8 \%$ \\
\hline \multicolumn{3}{|l|}{ Years in practice } \\
\hline $1-10$ & 179 & $43.3 \%$ \\
\hline $11-20$ & 86 & $20.8 \%$ \\
\hline $21-30$ & 96 & $23.2 \%$ \\
\hline$>30$ & 52 & $12.6 \%$ \\
\hline \multicolumn{3}{|c|}{ Number of caudal deviations seen per month } \\
\hline $0-2$ & 108 & $26.2 \%$ \\
\hline $3-5$ & 140 & $33.9 \%$ \\
\hline $6-15$ & 140 & $33.9 \%$ \\
\hline$>15$ & 25 & $6.1 \%$ \\
\hline
\end{tabular}

91.3\%), and half (51.3\%) of the respondents completed a facial plastic and reconstructive surgery (FPRS) fellowship. All respondents who completed an FPRS fellowship performed caudal septoplasty (Fig. 3). Respondents came either from academic (32\%), community $(54.2 \%)$ or other practice settings (13.8\%). A high proportion of respondents were in the beginning of their career $(<10$ years; $43.3 \%$ ), but the proportion of respondents who performed septoplasty was similar among all practitioners with less than 30 years of practice (1st-10th: 91.6\%; 11th-20th year: $94.2 \%$; 21st-30th: 93.8\%).

Of the respondents who saw the least caudal septal deviations in clinic (0-2 cases/month), $21.3 \%$ did not perform caudal septoplasty. Among respondents seeing 3 to 15 cases per month, less than $5 \%$ did not perform caudal septoplasty. (Fig. 4).

A vast majority of respondents use history and physical examination (96.9, and 99\%, respectively) to evaluate the degree of nasal obstruction. Only $26.6 \%$ of respondents use PROMs in their clinical practice. (Fig. 5).

The most popular surgical techniques were the swinging door technique (69.5\%), extracorporeal septoplasty (46.7\%), cartilage scoring (45.3\%), and splinting with bone $(25.4 \%)$. Other techniques were rarely employed (Fig. 6).

Surgeons who have completed an FPRS fellowship perform more caudal septoplasty than their counterparts ( $82 \%$ vs $100 \%, p<0.001)$. Surgeons with an FPRS background utilize more often the swinging door $(p<0.001)$, splinting $(p<0.001)$, extracorporeal septoplasty $(p<$ $0.001)$, and PDS plates $(p<0.001)$ than their counterparts. There was no difference in suture technique use between surgeons with or without an FPRS training background.

\section{Literature review}

The initial database search yielded a selection of 235 records, of which 26 were included in the qualitative synthesis after application of exclusion criteria (Fig. 2). These studies were published between 1994 and 2017. The number of patients included varied from 2 [8] to 703 [9] with a total of $n=1880$ cases (Table 2). Only four articles [12, 19, 20, 22] (15\%) included a control group.

Studies were classified by the surgical technique described. Since some records described a combination or sequence of surgical techniques, these records have been included simultaneously in multiple categories, as for the survey. To prevent classification errors, categories were precisely described before classifying each record, as follows: techniques that moved the lowermost part of the caudal septum to the midline or contralateral to the anterior nasal spine were categorized as a "swinging door technique". The "extracorporeal septoplasty" 


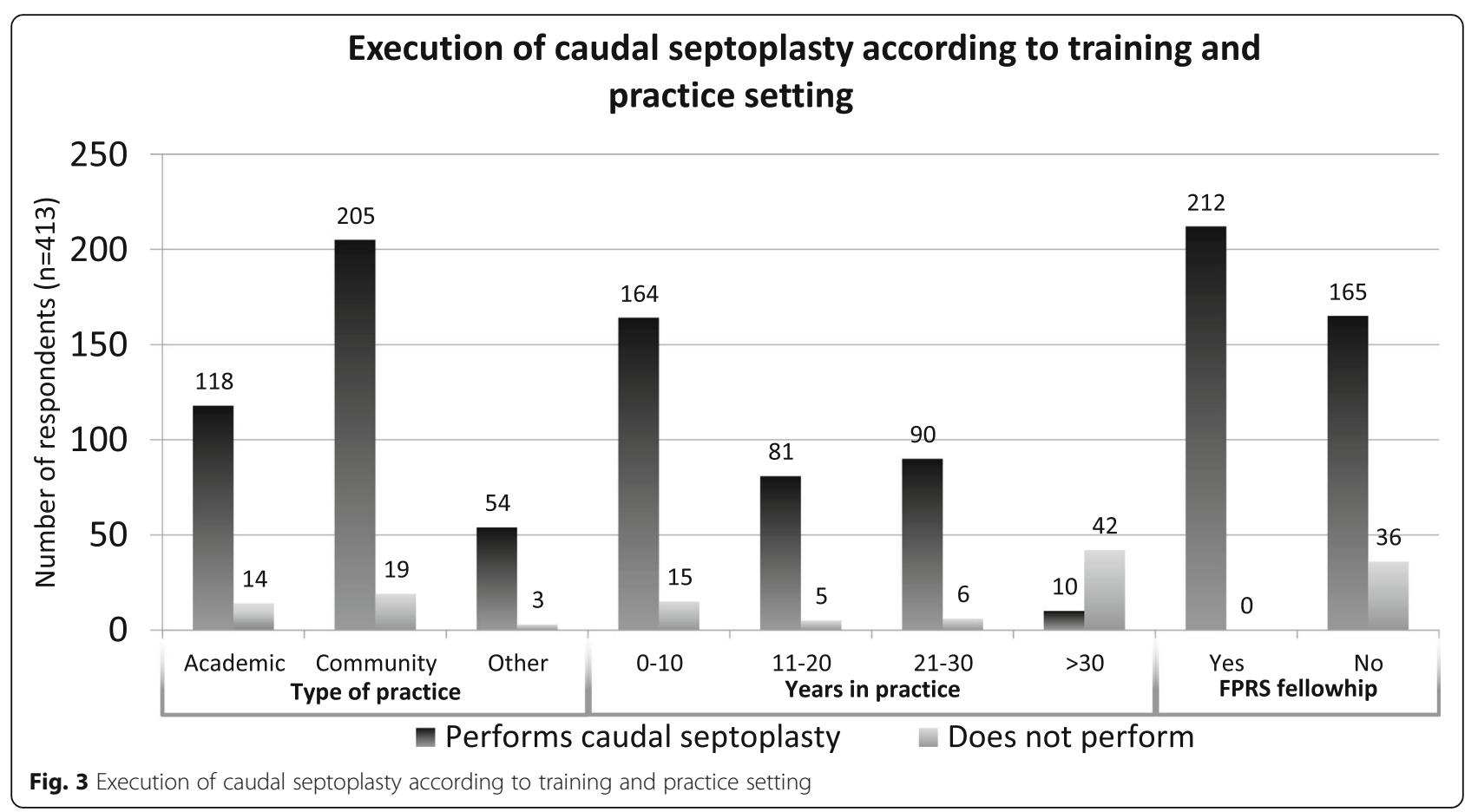

technique was defined as the removal of deviated cartilage with or without bony septum, followed by extracorporeal remodeling and subsequent reimplantation. The "splinting or grafting technique" includes cartilage splinting, and various bony or cartilaginous grafts used to stabilize the nasal septum. Cartilage grafts consisted either of posterior septal, quadrangular, costal or conchal cartilage. Bone grafts all consisted of bony batten grafts of various origins. "Suturing" regrouped all techniques consisting of permanent trans-cartilaginous retention sutures. "Scoring" techniques comprised all techniques where partial thickness incisions were made in the cartilage to overcome its natural bending forces.

Included records were also classified according to primary surgical outcome. Outcome was only functional for 15 records $[9-18,20-22,29,30]$ (58\%), while 11 [3, $8,19,23-28,31,32](42 \%)$ additionally evaluated esthetical outcomes.

As cited in $50 \%$ of the records, physical examination is the most popular way to evaluate post-operative relief of

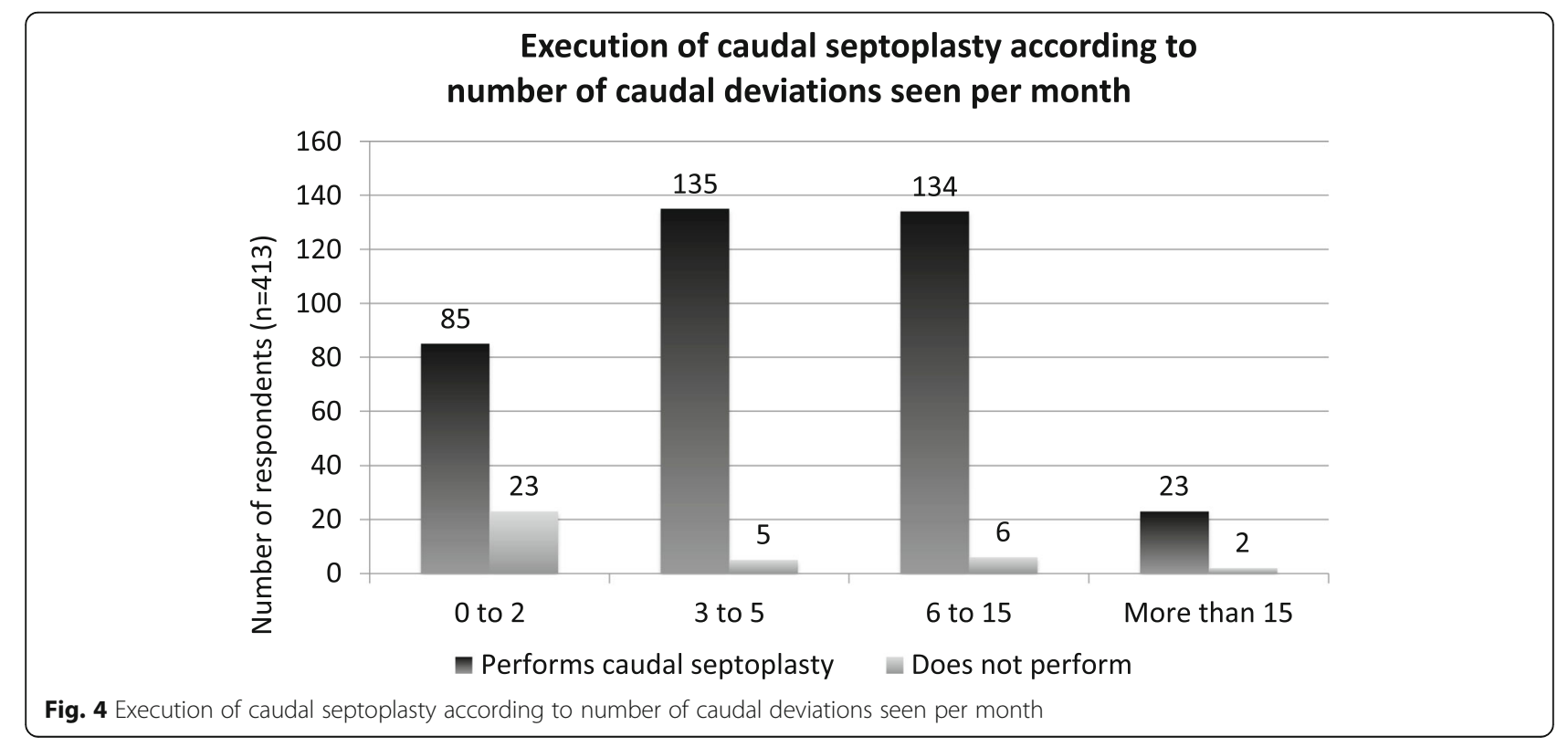




\section{Evaluation of caudal septal deviation by North American otolaryngologists and facial plastic surgeons}

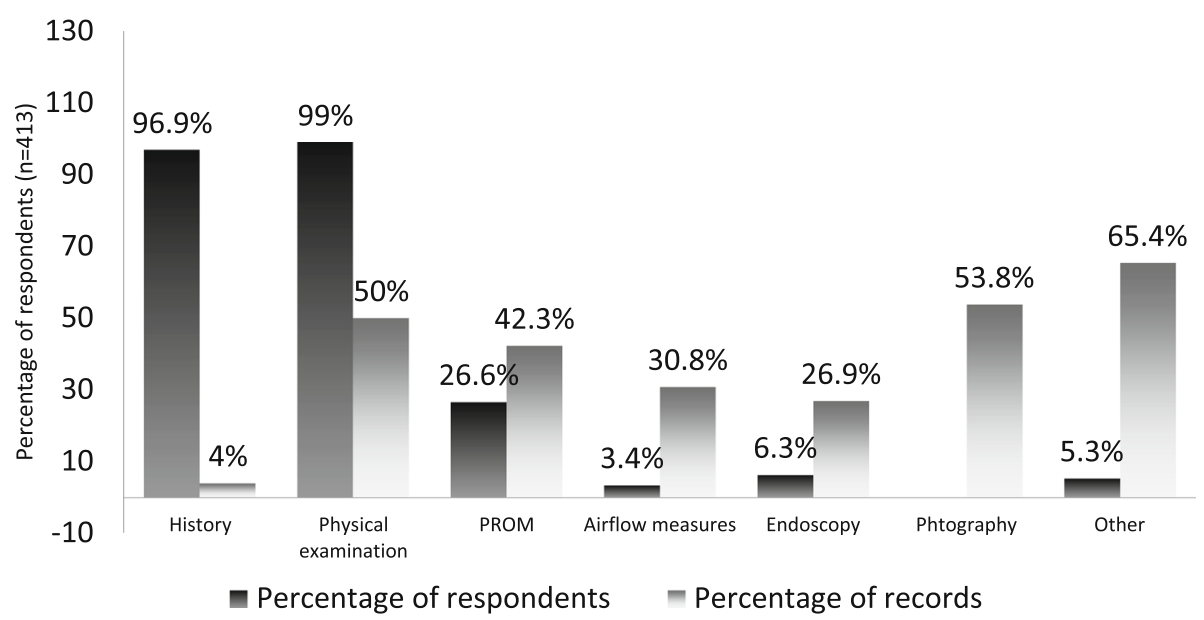

Fig. 5 Evaluation of caudal septal deviation by North American otolaryngologists and facial plastic surgeons

nasal obstruction. History taking was not explicitly cited in many articles, but the use of endoscopy (26.9\%), and airflow measure such as RM (7.7\%) or AR (23.1\%) were described (Fig. 7).

Administration of questionnaires was common (42.3\%), and the NOSE (30.8\%) was the most commonly used. The average results of the 8 studies $[15,19-21,24$, $26,30,33]$ that used the NOSE questionnaire were compared. The average calculated NOSE score was 19.3 post-operatively compared to 72.0 preoperatively for all techniques combined (Table 3). Aside from the NOSE, other PROMs such as the rhinoplasty outcome evaluation (ROE) [19, 31] $(7.7 \%)$, and the 16-item Sino-Nasal Outcome test (SNOT-16, 27) (3.8\%) were also reported. Custom questionnaires $(42.3 \%)$ were often used. Out of the 11 records using custom questionnaires $[3,9,10$, $12-14,18,21-23,25]$, only 3 [13, 21, 25] disclosed the questions and rating methods fully.

As previously mentioned, $11[3,8,19,23-28,31,32]$ (42.3\%) records evaluated cosmetic outcomes in addition to functional outcomes. Out of all the records, $53.8 \%$ reported a post-operative photographic analysis of the

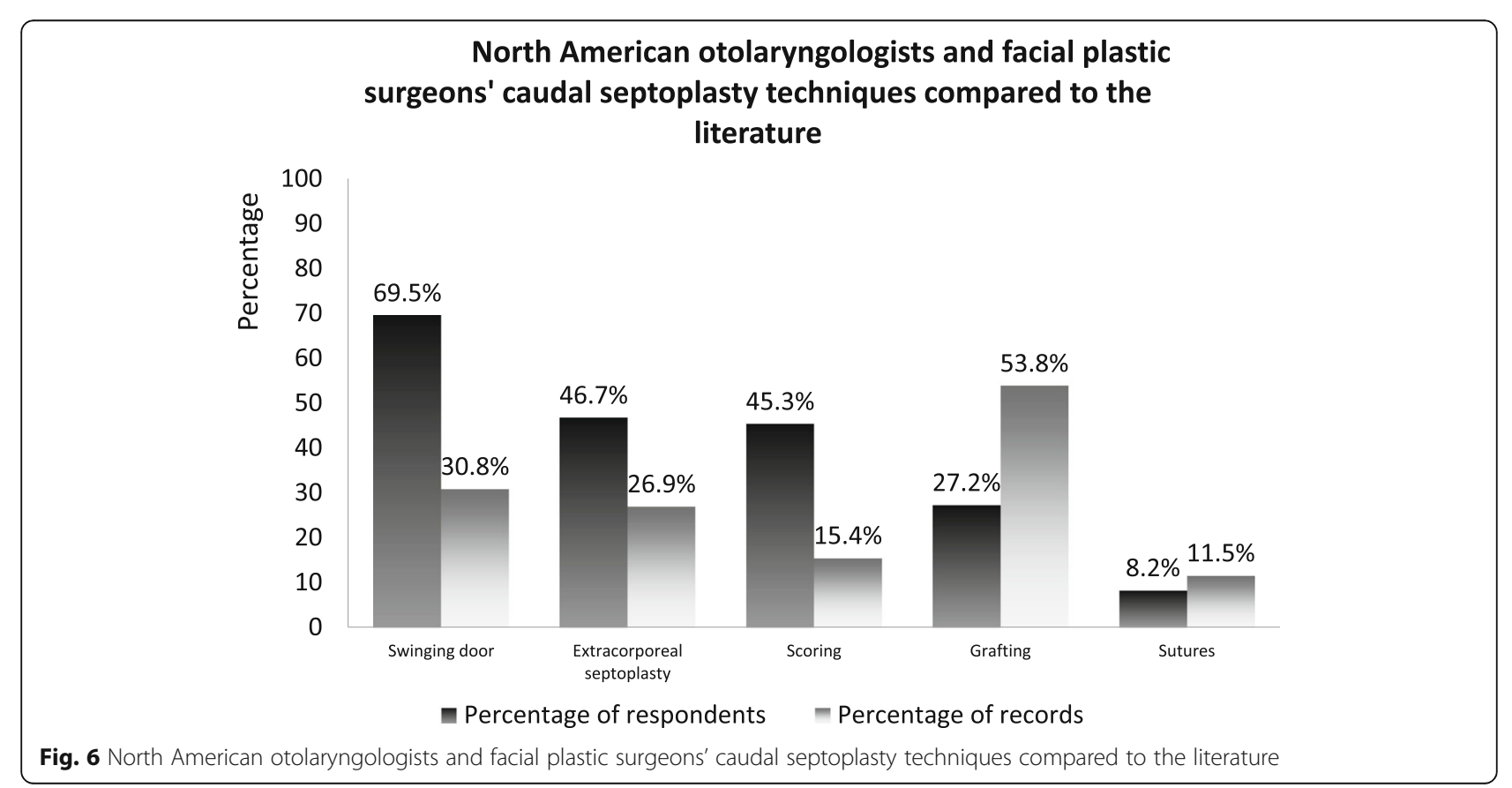


Table 2 Literature Review

\begin{tabular}{|c|c|c|c|}
\hline Author, year & Surgical Technique & Number of cases & Outcome evaluation methods \\
\hline Aboul Wafa. 2017 [10] & Swinging Door; Grafting & 18 & $C Q ; P A$ \\
\hline Akduman, D., et al. 2014 [11] & Swinging Door & 36 & PA \\
\hline Calderon-Cuellar, L. T., et al. 2004 [12] & Suturing; Scoring & 25 & $C E ; R M ; C Q$ \\
\hline Chung, Y. S., et al. 2014 [13] & Swinging Door; Grafting & 39 & $C E ; E ; A R ; V A S ; C Q$ \\
\hline Constantine, F. C., et al. 2014 [8] & Swinging Door; Grafting & 2 & PA \\
\hline Dyer, W. K. et al. 2000 [14] & Swinging Door; Grafting & 36 & $C E ; C Q ; P A$ \\
\hline Garcia, L. B., et al. 2001 & Grafting & 10 & CE; AR; NOSE; PA \\
\hline Giacomini, P., et al. 2010 [15] & Grafting; Scoring & 15 & CE; RM; NOSE; PA \\
\hline Indeyeva, Y. A., et al. 2017 [16] & Suturing; Other & 148 & $\mathrm{HPI}$ \\
\hline Jang, Y. J., et al. 2009 [17] & Grafting & 45 & E; VAS \\
\hline Kamami, Y. V. 1997 [18] & Other & 120 & $C E ; E ; A R ; C Q$ \\
\hline Kamami, Y. V., et al. 2000 [9] & Other & 703 & $C E ; E ; A R ; C Q$ \\
\hline Karadavut, Y., et al. 2017 [19] & Grafting & 20 & CE; AR; NOSE; ROE \\
\hline Kayabasoglu, G., et al. 2015 [20] & Extracorporeal & 45 & CE; NOSE; PA \\
\hline Kim, D. Y., et al. 2017 [21] & Grafting & 141 & E; NOSE; CQ \\
\hline Kim, J. H., et al. 2011 [22] & Grafting; Scoring & 56 & VAS; CQ \\
\hline Koch, C. A., et al. 2011 [23] & Extracorporeal; Grafting & 10 & CQ; PA; Other \\
\hline Lee, J. W., et al. 2013 [3] & Grafting & 66 & $C E ; C Q ; P A$ \\
\hline Loyo, M., et al. 2017 [24] & Extracorporeal & 71 & NOSE; PA \\
\hline Metzinger, S. E., et al. 1994 [25] & Swinging Door; Grafting & 10 & $C E ; C Q ; P A$ \\
\hline Most, S. P. 2006 [26] & Extracorporeal; Grafting & 12 & NOSE; PA \\
\hline Murrell, G. et al. 2000 [27] & Extracorporeal & 10 & $C E ; P A$ \\
\hline Sedwick, J. D., et al. 2005 [28] & Swinging Door & 62 & PA \\
\hline Shin, J. H., et al. 2011 [29] & Swinging Door; Suturing & 40 & AR; VAS \\
\hline Surowitz, J., et al. 2015 [30] & Extracorporeal & 77 & NOSE; VAS \\
\hline Yaniv, D., et al. 2017 [31] & Extracorporeal; Scoring & 63 & CE; E; ROE; SNOT-16 \\
\hline
\end{tabular}

CQ Custom questionnaire, PA Photographic analysis, CE Clinical examination, E Endoscopy, HPI History of present illness, RM Rhinomanometry, AR Acoustic rhinometry, VAS Visual assessment scale, NOSE Nasal Obstruction Symptom Evaluation, ROE: rhinoplasty outcome evaluation, SNOT-16 SinoNasal Outcome Test-16

\section{Surgical outcome measurement tools used by facial plastic surgeons and otolaryngologists in the literature and across North America}

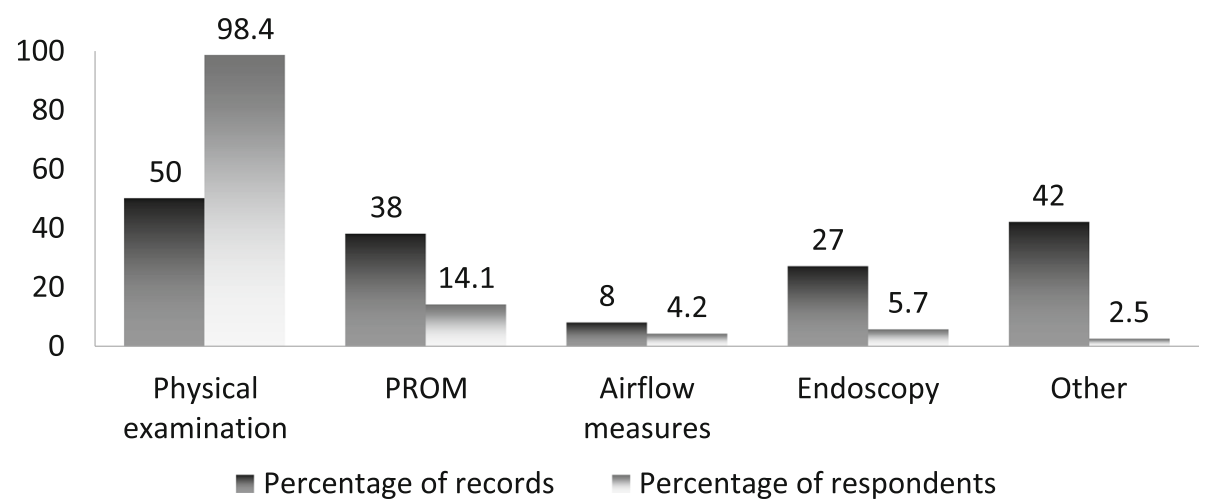

Fig. 7 Surgical outcome measurement tools used by facial plastic surgeons and otolaryngologists in the literature and across North America 
Table 3 Average preoperative and post-operative NOSE scores

\begin{tabular}{|c|c|c|c|c|}
\hline Author & Surgical Technique & Number of cases & Preoperative NOSE score & Postoperative NOSE score \\
\hline Garcia, L. B., et al. & Grafting & 10 & 82.7 & 7.4 \\
\hline Giacomini, P., et al. [15] & Grafting; Scoring & 15 & $57.4^{*}$ & $23.7^{\mathrm{a}}$ \\
\hline Karadavut, Y., et al. [19] & Grafting & 20 & 64.0 & 12.0 \\
\hline Kayabasoglu, G., et al. [20] & Extracorporeal & 45 & $85.0^{*}$ & $25.0^{\mathrm{a}}$ \\
\hline Kim, D. Y., et al. [21] & Grafting & 141 & 70.5 & 28.7 \\
\hline Loyo, M., et al. [24] & Extracorporeal & 71 & 72.3 & 24.0 \\
\hline Most, S. P [26]. & Extracorporeal; Grafting & 12 & 76.6 & 12.9 \\
\hline Surowitz, J., et al. [30] & Extracorporeal & 77 & 68.2 & 21.1 \\
\hline
\end{tabular}

${ }^{a}$ NOSE scores had to be recalculated because they were not reported according to standard NOSE score calculation within each article

nose. Of these, $21.4 \%[8,11,28]$ used photography as the only tool to quantify post-operative improvement, for both functional and esthetic outcomes. None used the SCHNOS.

\section{Discussion}

To our knowledge, this is the first survey in the literature to evaluate the use of caudal septoplasty techniques and outcome measurement tools. The aim of this descriptive study was to compare the different surgical techniques described in the literature to those used by surgeons today, especially with regards to the use of patient-reported outcome measures. As for any descriptive study, the objective is to portray current surgical trends rather than to draw conclusions regarding the efficacy of one technique over others.

Classifying caudal septoplasty techniques presents a challenge, due to the vast spectrum of minor surgical variations described in the literature to this day. As shown in Table 2, of the 26 records included in this systematic literature survey, only two $[9,18]$ could not be likened to one of the five most commonly used techniques. Other ones were variants of existing techniques. Although this regrouping relies on the reviewer's comprehension, which inevitably induces a bias, comparisons can be made. Figure 6 highlights that swinging door is more popular amongst survey respondents, whereas that grafting and splinting techniques were described more often in the literature. This could be attributable to a publication bias, since surgeons describing their techniques are more likely to be experts in their field, who rely on more complex surgical techniques in secondary or tertiary reference centers.

\section{Comparing the literature to survey answers}

A dual rationale underlies the comparison of survey answers and literature review results. First, it highlights a disparity between the techniques commonly being used by North-American otolaryngologists and facial plastic surgeons compared to what the literature depicts, which is presumably what is being done by experts in the field.
Essentially, a large toolbox exists, but surgeons in practice - $54 \%$ of which were community-based - may be focusing on mainly one technique, (swinging door, see Fig. 6). Why are surgeons preconizing technique when so many have been described? Reliable outcome data could allow the otolaryngologist or facial plastic surgeon to make an informed clinical choice. This leads to the second purpose of the comparison. It shines light on the fact that valid standardized tools such as PROMs aren't systematically used, either in practice nor in the literature. No one would do a stapedotomy without a preoperative audiogram, but surgeons operate on the deviated caudal septum without using standardised outcome assessment tools, both in clinical practice and in the literature.

\section{Comparing surgical outcomes}

Measuring performance in rhinoplasty can be a challenge, although previously published guidelines [34] recommend the utilization of PROMs at least 1 year after surgery. In the present systematic review, only 8 records used the NOSE score to compare preoperative and postoperative obstruction. Because of the relatively low number of patients and high heterogeneity between records, no valid meta-analysis has been possible.

Surprisingly, PROMs are not very prevalent in routine clinical practice, possibly due to logistic reasons. Moreover, the present study highlights that PROMs are used almost twice as frequently in the literature as they are by surgeons in their clinical practice (Fig. 5).

In October 2018, the American Society of Plastic Surgeons, in a joint effort with the AAFPRS and the AAOHNS released a set of performance measures for rhinoplasty and recommended that the SCHNOS questionnaire be administered at least preoperatively and 1 year postoperatively to rhinoplasty patients as a performance measure [34].

Comparing preoperative and postoperative PROM scores between one technique and another could provide with a simple surgical efficacy ranking. However, functional rhinoplasty is an operation where both cosmesis 
and function must be measured. In our systematic review, no study evaluated both form and function after caudal septoplasty using PROMs, rendering the evaluation of performance difficult. We recommend that future studies evaluating functional rhinoplasty techniques include both a pre- and postoperative evaluation of both form and function using a PROM that can evaluate both, such as the SCHNOS.

In the present study, we excluded records that did not report surgical outcomes. This criterion yielded a selection of mostly recent articles, published after 2010. Many older records were excluded for a lack of outcome evaluation. In the present literature review, custom questionnaires were used more commonly then PROMs.

\section{Conclusion}

In conclusion, our survey identified that caudal septoplasty is more commonly performed by surgeons with an FPRS training background. The most common techniques were the swinging door technique (69.5\%), extracorporeal septoplasy (46.7\%), cartilage scoring (45.3\%), and splinting with bone (25.4\%). Our systematic review identified no studies that evaluated both functional and cosmetic outcomes of any technique with validated outcome measurement tools. We recommend that future studies of caudal septoplasty include an assessment of both form and function using a validated PROM such as the SCHNOS, as recommended by the American Society of Plastic Surgeons.

\section{Acknowledgements}

The authors want to thank Jocelyne Fortin (ORLQC); Kim Iverson and Donna Humphrey (CSOHNS); Leigh McGuire and Fatima Porter El Mitchell (AAFPRS) for their collaboration in distributing this survey to the members of their associations.

\section{Authors' contributions}

Béatrice Voizard: contributed largely to study design, contributed to literature reviewing, was responsible for data collection and was a major contributor in writing and revising the manuscript. Melanie Theriault: contributed to literature reviewing, contributed to data collection and was a minor contributor in writing the manuscript. Selma Lazizi: contributed to study design, contributed to literature reviewing, contributed to data collection and was a minor contributor in writing the manuscript. Sami P. Moubayed: contributed largely to study design, overviewed literature review and data collection and was a major contributor in writing and revising the manuscript. The author (s) read and approved the final manuscript.

\section{Funding}

The authors received no funding for the study and collection, analysis, and interpretation of data nor for writing the manuscript.

\section{Availability of data and materials}

The datasets used and analyzed during the current study are available from the corresponding author on reasonable request.

\section{Ethics approval and consent to participate}

This study was performed in accordance to the Declaration of Helsinki and was approved by an institutional review board (IRB): the ethical committee of the Research Center at CIUSSS de I'Est-de-I'Tle-de-Montréal, Installation Maisonneuve-Rosemont, which a teaching hospital affiliated with our institution. The project number is 2018-1237.

\section{Consent for publication}

Consent for publication was obtained with each participant, at the time of answering the survey. This was approved by the IRB.

\section{Competing interests}

The authors declare that they have no competing interests.

Received: 9 February 2020 Accepted: 1 June 2020

Published online: 08 June 2020

\section{References}

1. Most SP, Rudy SF. Septoplasty: basic and advanced techniques. Facial Plast Surg Clin North Am. 2017;25(2):161-9.

2. Moubayed SP, Most SP. Correcting deviations of the lower third of the nose Facial Plast Surg : FPS. 2017;33(2):157-61.

3. Lee JW, Baker SR. Correction of caudal septal deviation and deformity using nasal septal bone grafts. JAMA Facial Plast Surg. 2013;15(2):96-100.

4. Kim CS, Moon BK, Jung DH, Min YG. Correlation between nasal obstruction symptoms and objective parameters of acoustic rhinometry and rhinomanometry. Auris Nasus Larynx. 1998;25(1):45-8.

5. Moubayed SP, loannidis JPA, Saltychev M, Most SP. The 10-item standardized Cosmesis and health nasal outcomes survey (SCHNOS) for functional and cosmetic Rhinoplasty. JAMA Facial Plast Surg. 2018;20(1): 37-42.

6. Moher D, Liberati A, Tetzlaff J, Altman DG. Preferred reporting items for systematic reviews and meta-analyses: the PRISMA statement. Int J Surg. 2010;8(5):336-41.

7. Liberati A, Altman DG, Tetzlaff J, Mulrow C, Gotzsche PC, loannidis JP, et al. The PRISMA statement for reporting systematic reviews and meta-analyses of studies that evaluate health care interventions: explanation and elaboration. PLoS Med. 2009;6(7):e1000100.

8. Constantine FC, Ahmad J, Geissler P, Rohrich RJ. Simplifying the management of caudal septal deviation in rhinoplasty. Plast Reconstr Surg. 2014;134(3):379e-88e

9. Kamami YV, Pandraud L, Bougara A. Laser-assisted outpatient septoplasty: results in 703 patients. Otolaryngol Head Neck Surg. 2000;122(3):445-9.

10. Aboul Wafa AM. Forked Columellar strut: an adjunctive technique for correction of caudal Septal deviation. Plast Reconstr Surg Glob Open. 2017; 5(5):e1347.

11. Akduman D, Haksever M, Yanilmaz M. Repositioning of the caudal septal dislocations with notching and suturing the cartilage to the nasal spine. Eur Arch Otorhinolaryngol. 2014:271(1):81-5.

12. Calderon-Cuellar LT, Trujillo-Hernandez B, Vasquez C, Padilla-Acero J, Cisneros-Preciado $\mathrm{H}$. Modified mattress suture technique to correct anterior septal deviation. Plast Reconstr Surg. 2004;114(6):1436-41.

13. Chung YS, Seol JH, Choi JM, Shin DH, Kim YW, Cho JH, et al. How to resolve the caudal septal deviation? Clinical outcomes after septoplasty with bony batten grafting. Laryngoscope. 2014;124(8):1771-6.

14. Dyer WK, Kang J. Correction of severe caudal deflections with a cartilage 'plating' rigid fixation graft. Arch Otolaryngol Head Neck Surg. 2000;126(8): 973-8.

15. Giacomini P, Lanciani R, Di Girolamo S, Ferraro S, Ottaviani F. Caudal septal deviation correction by interlocked graft technique. Ann Plast Surg. 2010; 65(3):280-4

16. Indeyeva YA, Lee TS, Gordin E, Chan D, Ducic Y. Traction suture modification to tongue-in-groove caudal septoplasty. Int J Oral Maxillofac Surg. 2018;47(2):180-83. https://doi.org/10.1016/j.ijom.2017. 06.007

17. Jang YJ, Yeo NK, Wang JH. Cutting and suture technique of the caudal septal cartilage for the management of caudal septal deviation. Arch Otolaryngol Head Neck Surg. 2009;135(12):1256-60.

18. Kamami YV. Laser-assisted outpatient septoplasty results on 120 patients. J Clin Laser Med Surg. 1997;15(3):123-9.

19. Karadavut $Y$, Akyildiz I, Karadas H, Dinc AE, Tulaci G, Tastan E. Effectiveness of caudal septal extension graft application in endonasal septoplasty. Braz J Otorhinolaryngol. 2017;83(1):59-65.

20. Kayabasoglu G, Nacar A, Yilmaz MS, Altundag A, Guven M. A novel method for reconstruction of severe caudal nasal septal deviation: marionette septoplasty. Ear Nose Throat J. 2015;94(6):E34-40. 
21. Kim DY, Nam SH, Alharethy SE, Jang YJ. Surgical outcomes of bony batten grafting to correct caudal septal deviation in Septoplasty. JAMA Facial Plast Surg. 2017;19(6):470-5.

22. Kim JH, Kim DY, Jang YJ. Outcomes after endonasal septoplasty using caudal septal batten grafting. Am J Rhinol Allergy. 2011;25(4):e166-70.

23. Koch CA, Friedman O. Modified back-to-back autogenous Conchal cartilage graft for caudal septal reconstruction. Arch Facial Plast Surg. 2011;13(1):20-5.

24. Loyo M, Markey JD, Gerecci D, El Rassi E, Li RJ, Sullivan CB. et al, Technical refinements and outcomes of the modified anterior septal transplant. JAMA Facial Plast Surg. 2018;20(1):31-6.

25. Metzinger SE, Boyce RG, Rigby PL, Joseph JJ, Anderson JR. Ethmoid bone sandwich grafting for caudal septal defects. Arch Otolaryngol Head Neck Surg. 1994;120(10):1121-5.

26. Most SP. Anterior septal reconstruction: outcomes after a modified extracorporeal septoplasty technique. Arch Facial Plast Surg. 2006;8(3):202-7.

27. Murrell GL, Requena R, Wall MP. Septal replacement for severe anterior septal deviation. Am J Otolaryngol. 2000;21(3):147-52.

28. Sedwick JD, Lopez AB, Gajewski BJ, Simons RL. Caudal septoplasty for treatment of septal deviation: aesthetic and functional correction of the nasal base. Arch Facial Plast Surg. 2005;7(3):158-62.

29. Shin JH, Lee MH, Kim YH, Kim SW, Kim SW, Cho JH, et al. Wedge resection and modified mattress suture for correcting anterior septal deviation: how we do it. Clin Otolaryngol. 2011;36(5):504-9.

30. Surowitz J, Lee MK, Most SP. Anterior Septal reconstruction for treatment of severe caudal Septal deviation: clinical severity and outcomes. Otolaryngol Head Neck Surg. 2015;153(1):27-33.

31. Yaniv D, Hadar T, Hod R, Lansberg R, Koren I, Yaniv E. Repair of caudal septal deviation: the fishing line technique. Int Forum Allergy Rhinol. 2017; 7(2):211-4.

32. Garcia LB, Oliveira PW, Vidigal Tde A, Suguri Vde M, Santos Rde P, Gregorio LC. Caudal septoplasty: efficacy of a surgical technique-preliminary report. Braz J Otorhinolaryngol. 2011;77(2):178-84.

33. Garcia GJ, Rhee JS, Senior BA, Kimbell JS. Septal deviation and nasal resistance: an investigation using virtual surgery and computational fluid dynamics. Am J Rhinol Allergy. 2010;24(1):e46-53.

34. Rohrich RM, M. Rhinoplasty Performance Measurement Set. Performance measure report. New Orleans: American Society of Plastic Surgeons; 2018 2018-09-26.

\section{Publisher's Note}

Springer Nature remains neutral with regard to jurisdictional claims in published maps and institutional affiliations.

Ready to submit your research? Choose BMC and benefit from:

- fast, convenient online submission

- thorough peer review by experienced researchers in your field

- rapid publication on acceptance

- support for research data, including large and complex data types

- gold Open Access which fosters wider collaboration and increased citations

- maximum visibility for your research: over $100 \mathrm{M}$ website views per year

At $\mathrm{BMC}$, research is always in progress.

Learn more biomedcentral.com/submissions 